\title{
Pilar Goya \\ Designada Membro Honorário da RSC
}

Pilar Goya, Vice-Presidente da EuChemS, foi agraciada com a designação de Membro Honorário da Royal Society of Chemistry em 2020. Existem atualmente mais de uma centena de Membros Honorários, tendo a sua admissão como base o reconhecimento pelas suas contribuições notáveis para o avanço das ciências químicas. Mais detalhes sobre esta distinção podem ser encontrados em euchems.eu/ pilar-goya-honorary-fellow-rsc.

$>$

Bruno Machado

brunofm@fe.up.pt

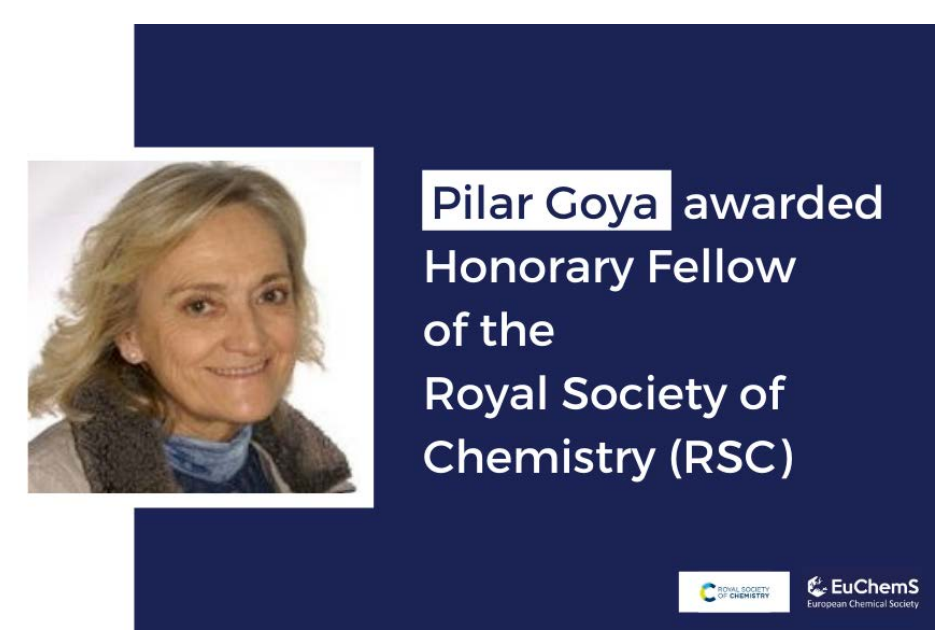

\section{Prémio}

IUPAC-CHEMRAWN VII 2020

As investigadoras Huizhen Liu (Instituto de Química da Academia Chinesa de Ciências, China) e Banothile Makhubela (Universidade de Joanesburgo, África do Sul) foram agraciadas com o Prémio IUPAC-CHEMRAWN VII 2020 de Química Verde em reconhecimento pelas suas contribuições notáveis para a área.

0 trabalho da Dr.a Makhubela centra-se na conversão de gases com efeito estufa e matérias primas vegetais em produtos de valor acrescentado, bem como abordagens computacionais para clarificar como as moléculas interagem entre si. Este trabalho contribui para a meta de desenvolvimento sustentável de produção e consumo responsáveis. 0 trabalho da
Dr. ${ }^{a}$ Huizhen Liu foca-se na transformação do $\mathrm{CO}_{2}$ e biomassa. Ela é reconhecida pelo seu trabalho com transformações catalíticas seletivas da lignina, que abrem o caminho para a produção de produtos de valor acrescentado a partir desta macromolécula.

O Prémio CHEMRAWN VII foi atribuído pela primeira vez em agosto de 2008 e, desde então, tem sido concedido a cada dois anos na Conferência Internacional da IUPAC em Química Verde. O Prémio é concedido a um jovem investigador (com menos de 45 anos) de uma região emergente que contribua ativamente para a investigação em Química Verde.

$>$

Bruno Machado

brunofm@fe.up.pt 